\title{
Tattoo-Associated Skin Reactions - Clinical Cases
}

\author{
Fekete GyL¹, Fekete Júlia Edit² \\ ${ }^{1}$ Department of Dermatology, University of Medicine and Pharmacy, Tîrgu Mureș, Romania \\ 2 Public Health Center, Tîrgu Mureș, Romania
}

Tatooing has been practiced for thousands of years. It has become a common practice for people of Western countries in the last 10-20 years, where approximately 3-5\% of the population has at least one tattoo. Various pigmented substances introduced into the skin may cause the occurrence of adverse irritative, immunological, infectious or other reactions of the skin. We present three clinical cases with adverse reactions after tattooing.

Keywords: tattoo, contact dermatitis, laser

Received: 21 March 2013

\section{Introduction}

Tatooing has been practiced for thousands of years. In the past they were used mostly for decoration, while in some countries and cultures tattooing has been a hallmark for different social ranks. It has become common practice for people of all Western countries over the last 10-20 years, where approximately $3-5 \%$ of the population has at least one tattoo. Recently this phenomenon is also found more frequently in Romania.

A tattoo is made by inserting pigment by means of a needle into the dermis layer of the skin. The introduction of foreign substances into the skin can produce irritative, immunological, infectious or other reactions of the skin. We present three clinical cases with adverse reactions occurring after tattooing.

\section{Case reports}

\section{Case 1}

A 19 year-old female patient developed a well-defined erythemato-vesiculos eruption on the surface of a tattoo that was made on the back of the neck (Figure 1). This acute inflammatory reaction associated with severe itching occurred within approximately 48 hours after the tattoo. With application of local corticosteroid and systemic antihistamines, skin lesions and symptoms resolved within a week.

\section{Case 2}

A 27 year-old patient was consulted for the presence of multiple round-oval, flesh-colored papules with diameters ranging from 1 to $2.5 \mathrm{~mm}$, strictly localized on the surface of a tattoo located on the lower back (Figure 2). The lesions were diagnosed as flat warts, and occurred after 3 years from the date of the tattoo. Treatment consisted of electrocautery of the lesions.

\section{Case 3}

A 29 year-old female patient was admitted to our outpatient clinic because of a round painless tumor with hard consistency about $1.5 \mathrm{~cm}$ in diameter, located strictly on

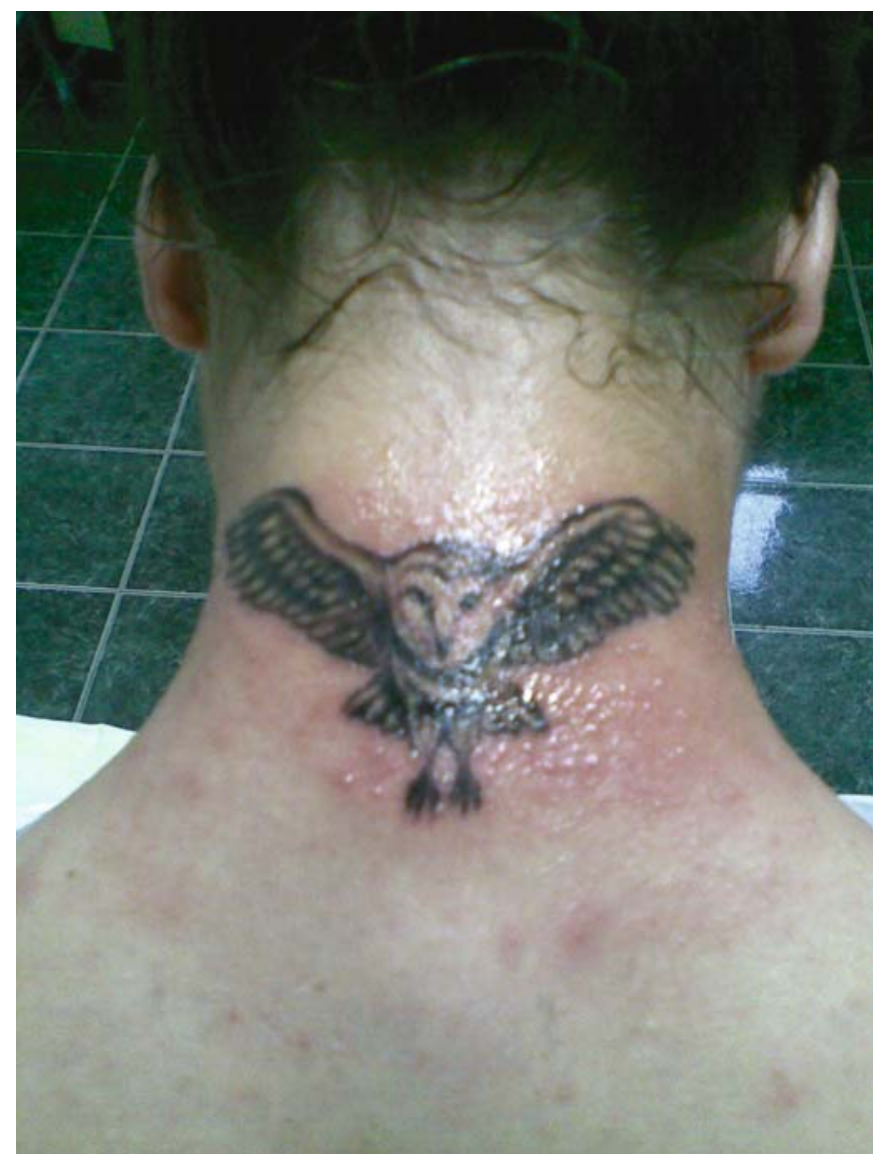

Fig. 1. Case 1-clinical aspect 


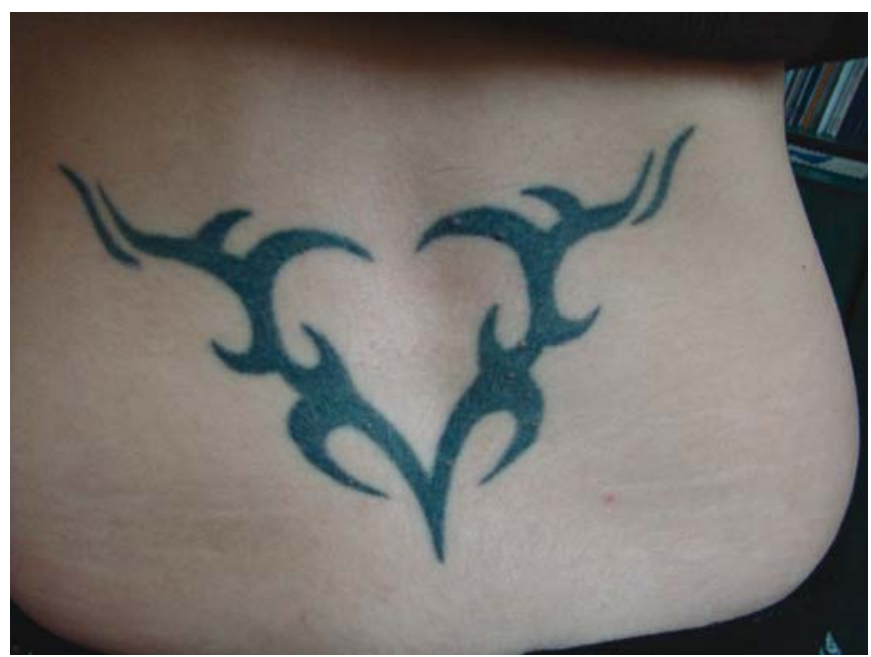

Fig. 2. Case 2 - clinical aspect

the surface of a tattoo that was made on the pretibial area of the right leg (Figure 3). The patient developed this reaction slowly, in the course of several months to 6 years after the tattoo. The presumptive diagnosis was granulomatous reaction. The lesion was excised completely. The histopathological examination described dense lymphocytic infiltrate in the upper dermis, with few eosinophils and histiocytes. Immunohistochemistry detected a prevalence of CD3+ lymphocytes and a small proportion of CD22+ cells. Based on these facts a pseudolymphomatous reaction was diagnosed. Regular control was recommended for the patient.

\section{Discussion}

Tattooing is defined as accidental or voluntary deposit of pigment in the skin. Accidental or professional tattoos are met in miners, metallurgists, stonemasons, millers etc.. The voluntary tattoo, or tattoo itself, is the introduction of pigment into the dermis with a needle. The composition of pigments used in tattoos may contain either metal salts or organic compounds [1]. Some examples: the red color comes from mercury sulphide (Cinnabar), ferric hydrate or Brazilian wood and sandalwood, the black color from carbon (India ink) or iron oxide, the blue from cobalt aluminate, the green from chromic oxide, lead chromate, phthalocyanine dye, the white from titanium oxide, zinc oxide, etc.. With the increasing number of people with tattoos there has appeared a growing number of skin manifestations associated with tattoos. These symptoms can be varied, with irritation or immunological reactions, like fotoinduced, granulomatous, lichenoid or pseudolymphomatous reactions, etc., and a variety of bacterial or viral infections $[2,3]$.

\section{Acute and chronic inflammatory reactions}

This is a frequent side effect of the tattooing process, due to physical injury to tissue and the injection of pigment into the skin. Erythema and swelling appears, that disappears within 2-3 weeks. Delayed reactions, most often contact dermatitis, occur several weeks or years after the tattoo. They present clinically as a chronic eczema. Red tattoos,

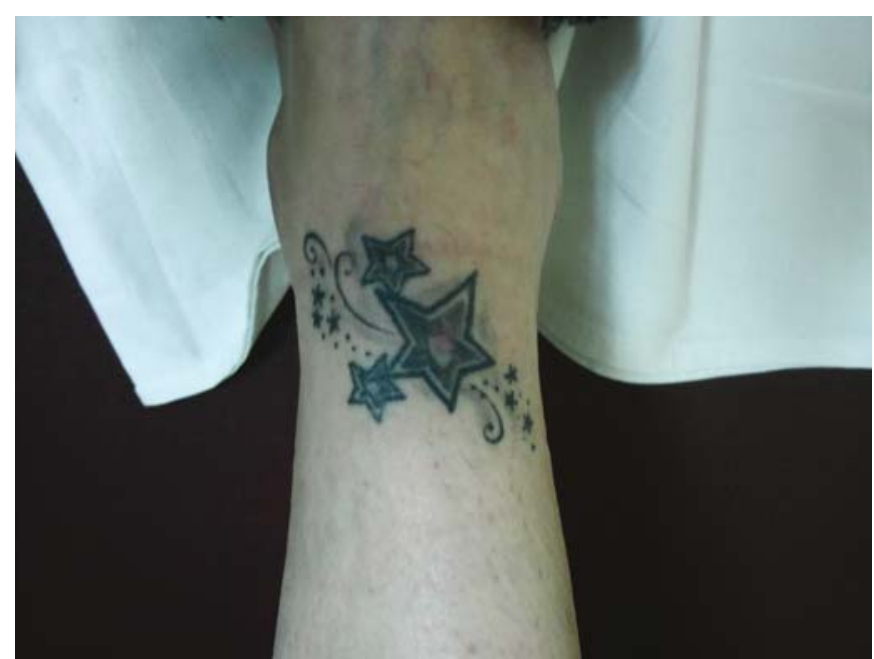

Fig. 3. Case 3-clinical aspect

especially those containing mercury, are the most common causes of contact dermatitis. Hypersensitive reactions to black, blue, purple and green pigment are less common [4].

\section{Photoinduced reactions}

Yellow tattoos, consisting mainly of cadmium sulphate, are most commonly associated with photoinduced reactions, manifested clinically by the appearance of pruritic erythematous nodules.

\section{Granulomatous reactions}

Granulomatous reactions appear as foreign body reactions to inserted pigment. In most cases red tattoo pigments (mercury) as well as green, blue (cobalt) or purple (manganese) are associated with granulomatous reactions.

\section{Lichenoid reactions}

Lichenoid tattoo reactions resemble lichen planus, showing typical polygonal papules with ribs, confluated sometimes into a purpleish plaque. Histologic examination shows a typical aspect of lichen planus. Red pigment (mercury) is most commonly involved in lichenoid reactions.

\section{Pseudolimfomatoase reactions}

They are the result of delayed hypersensitive reactions to tattoo pigment. Clinically they manifest as hardened nodules or erythematous or violaceous plaques within the tattoo. They must be distinguished from cutaneous lymphomas. Histopathologically in the upper dermis there is a mixed cellular infiltrate and well represented vascularity. In this type of reaction the lymphocytic infiltrate is polyclonal, in comparison with malignant lymphoma where it is monoclonal. Red pigment is incriminated as the main cause in the occurrence of this adverse effect $[5,6]$.

\section{Infections}

Infectious complications are rare and usually occur immediately after execution. Pyogenic skin infections are second- 
ary due to epidermal barrier breakdown. There has been reported the occurrence of various infections caused by tatooing, such as pyoderma, impetigo, cellulitis, erysipelas, mycobacterial infection, syphilis and leprosy $[7,8,9]$. Some viral infections were noted as rare infections with herpes simplex virus, papilloma virus (warts), poxvirus (molluscum) and systemic infection with hepatitis B, C and HIV $[10,11,12,13]$. The infection is mainly due to poor hygiene conditions at the time the tattoo was executed.

\section{Other manifestations}

In the literature several clinical cases with malignant skin tumors among tattoos, like lymphoma type B, melanoma, basal cell and squamous cell carcinomas have been published.

\section{Tattoo removal}

Tattoos are usually treated with Q-switched LASER. This treatment requires several sessions (about 10-12) organized over a period of 6-8 weeks [14]. Laser treatment can also be selected according to the color pigment of the tattoo [15]:

- Nd: YAG (1064 nm) for black and blue pigment;

- Alexandrite $(755 \mathrm{~nm})$ for black, blue and green pigments;

- Ruby (694 nm) for black, blue and green pigments;

- Frequency doubled Nd: YAG (532 nm) for red, orange and purple pigments;

- Flashlamp-pumped pulsed dye $(510 \mathrm{~nm})$ for red, purple, orange and yellow pigments.

LASER-therapy may be followed by complications, such as hypertrophic scars and/or keloids, changes of the skin pigmentation, etc.

\section{Conclusions}

Tattooing can be followed by the emergence of various skin manifestations, which also can be infectious. Complete tattoo removal is not always possible despite the availablity of several types of possible treatments.

\section{References}

1. Bucur Gh. Boli dermatovenerice. Enciclopedie. Editura Medicală Națională, București, 2002;808.

2. Jacob Cl. Tattoo-associated dermatoses: a case report and review of the literature. Dermatol Surg. 2002;28:962-5.

3. Oanță A, Irimie M. Dermatoze associate tatuajelor. Observație asupra a două cazuri. Dermato Venerol. (Buc.), 2008;53:163-166.

4. Raison-Peyron N, Meunier L, Vian L, et al. Eczema de contact a un tatuage labile contenant du henne. Ann Dermatol Venereol. 2000;127:1083-6.

5. Gutermuth J, Hein R, Fend F, et al. Cutaneous pseudolymphoma arising after tattoo placement. J Eur Acad Dermatol Venereol. 2007;21(4):566-7.

6. Kluger N, Vermeulen C, Moguelet P, et al. Cutaneous lymphoid hyperplasia (pseudolymphoma) in tattoos: a case series of seven patients. J Eur Acad Dermatol Venereol. 2010;24(2):208-13

7. Long GE, Rickman LS. Infectious complications of tattoos. Clin Inf Dis 1994;18:610-9.

8. Ghorpade A. Tattoo inoculations lupus vulgaris in two Indian ladies. J Eur Acad Dermatol Venereol. 2006;20:476-7.

9. Ghorpade A. Inoculation (tattoo) leprosy: a report of 31 cases. J Eur Acad Dermatol Venereol. 2002;16:494-9.

10. Ragland HP, Hubbell C, Stewart KR, et al. Verruca vulgaris inoculated during tattoo placement. Int J Dermatol. 1994;33:796-7.

11. Trefzer U, Schmollack KP, Stockfleth E, et al. Kolde G. Verrucae in a multicoloured decorative tattoo. J Am Acad Dermatol. 2004;50:478-9.

12. Salmaso F, Gnecchi L, Gianotti R, et al. Molluscum contagiosum on a tattoo. Acta Derm Venereol. 2001;81:146-7.

13. Perez Gala S, Alonso Perez A, Rios Buceta L. Molluscum contagiosum on a multicoloured tattoo. J Eur Acad Dermatol Venereol. 2006;20:221-2.

14. Kuperman-Beade M, Levine VJ, Ashinoff R. Laser removal of tattoos. Am J Clin Dermatol. 2001;2:21-25.

15. Burns T, Breathnach S, Cox N, et al. Rook's Textbook of Dermatology. Eight Edition. Wiley-Blackwell Scientific Publications. 2010 